\title{
A Study on Analysis \& Outlook of Smart City based on Actual Cases
}

\author{
Seong-Hoon Lee ${ }^{1}$ and Dong-Woo Lee ${ }^{2 *}$ \\ ${ }^{1}$ Division of Information\&Communication, Baekseok University, 115, Anseo-dong, \\ Cheonan, Choongnam, Korea \\ ${ }^{2 *}$ Dept. Of Computer Information, Woosong University, 226-2, Jayang-dong, \\ Dong-gu, Daejon, Korea \\ 1shlee@bu.ac.kr, ${ }^{2} d w l e e @ w s u . a c . k r$
}

\begin{abstract}
ICT convergence fields include various regions. In this paper, we described a smart city which was leading case in digital convergence and related with our life.During the last decades, cities have become increasingly central in the economic, social, and development-related processes. Since 1990 the term Smart City has been spreading in conjunction with the liberalization of telecommunications and the development of services provided through the internet. We described actual cases of smart city in Europe and Asia, and focused on analysis and applicability of current smart city in this paper.
\end{abstract}

Keywords: ICT, Smart City, Intelligence, Smart, Urbanization

\section{Introduction}

We commonly call the modern society as "digital convergence". Digital convergence combines existing industry with IT to create new values and even industrial structure. Especially, mobile, smart, cloud computing can be called core technologies of the large technological direction of convergence that "smart" is receiving spotlight as convergence is deepening [1,2,4].The proactive meaning of smart is 'wise', 'clever', and etc.

However, smart means high intelligence of individuals and industry as a social economic phenomenon. The core characteristic of smart is 'intelligence', but not only this characteristic mean the smart era. The smart era did not suddenly appear, but had appeared as a new paradigm as network of the internet era, mobility of the ubiquitous era, intelligent IT of the convergence era had converged.

Smart technology creates new business in each industry and will be the role of continuous development. Non-existing or impossible new changes in industry have taken place as several smart technologies have been applied in industry areas. These new businesses will create new businesses of smart industry through convergence, and will continuously develop. In this paper, we reviewed on smart city.

Smart city means a city where public functions available in common cities are networked by means of cutting-edge information/communication technology. Functions necessary for the realization of ICT-based smart city include concepts of sensor-based ubiquitous environment and intelligence [3,8]. Smart city is, in other terms, a futureoriented advanced city that is pursued around the world as the fruit of ICT-based convergence industry. To realize such smart city, a large-scale project widely applicable from basic industries such as environment, transportation, utility, and construction to specific home appliances need to be developed. Since 2007 when i-Phone of Apple was released, the term 'Smart,' beginning with smart phones, has been widely used in combination with names of other devices such as smart TV, smart car, etc. The area has gradually expanded to other areas such as smart home, smart energy, smart building, 
smart transportation, smart shipbuilding, etc. More recently, a concept of 'Smart City' that embraces an entire city has emerged.

Devices with the term 'Smart' all include interconnection functions through which they exchange information with people or other objects in addition to the basic computer functions[9]. In addition, the universal OS embraces various types of application programs that provide various functions.

Hence, devices with the term 'Smart' feature the convergence, expansibility, and information exchange with other entities as well as computer-based functions. Smart city as well embodies interconnecting functions among internal members, objects, and cities based on information/communication technology and adopt various convergence technologies just as other Smart devices do. In this sense, it too reflects the meaning of 'Smart.'

It is reported that more than $50 \%$ of the entire world population are living in cities[10]. According to Navigant Research, an energy \&green industry market investigator, it is expected that during the following 40 years, the rates of urbanization and population increase will drastically be increased[9-10]. Figure 1 shows the evolution of world's population and rate of urban citizen. According to the 2012 revision of the official United Nations population estimates and projections, the world population of 7.2billion in mid2013 is projected to increase by almost one billion people within the next twelve years, reaching 8.1 billion in 2025, and to further increase to 9.6 billion in 2050 [10]. Such increase in urban populations will be especially outstanding among developing countries, and excessive urbanization and explosive increase of urban populations will move urbanization to the next level, that is, inevitably to the level of smart city.

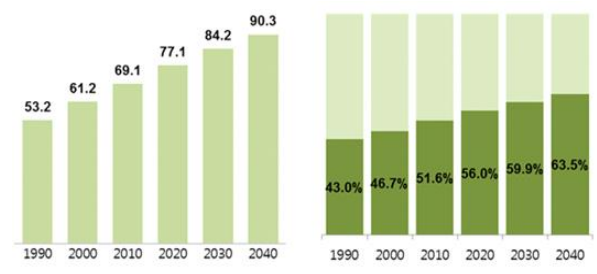

Figure 1. Evolution of World's Population (Unit: One Hundred Million and Rate of Urban Citizen (UN: 2013)

This study comprehensively examines actual cases of abroad Smart City where we live and enjoy most of the daily activities in digital convergence environments. In comparison with the current smart city, the future direction is also briefly presented

\section{Smart City Components}

Smart city began as Internet-based cyber city in computers and has advanced to the current status [5]. The framework of smart city, as shown in Figure 2, consists of the sixelements: smart government, smart building, smart mobility[6-7], smart energy, environment and smart service.

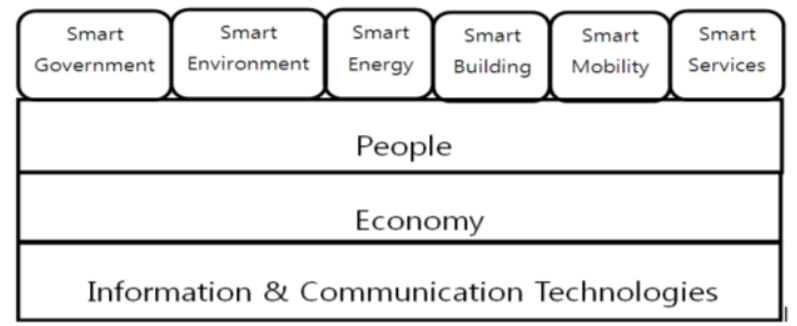

Figure 2. Smart City Components 
The function of each component was represented by the following Table 1 .

Table 1. Function of Six Components

\begin{tabular}{|c|c|}
\hline Elements & function \\
\hline Smart Government & 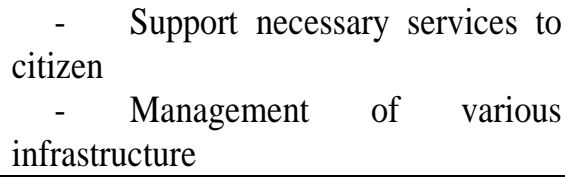 \\
\hline Smart Energy & $\begin{array}{ll}- & \text { Means smart grid } \\
- & \text { Basic energy infrastructure }\end{array}$ \\
\hline Smart Environment & $\begin{array}{ll}- & \text { Environmentally-friendly } \\
\text { factors } & \\
- & \text { Green IT } \\
\end{array}$ \\
\hline Smart Building & $\begin{array}{l}\text { - Control automatically by } \\
\text { sensors } \\
-\quad \text { Provide buildings with clean } \\
\text { and economic environment }\end{array}$ \\
\hline Smart Mobility & 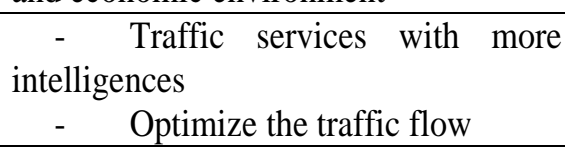 \\
\hline Smart Services & $\begin{array}{ll}\text { - } & \text { Service type provided to } \\
\text { citizen } & \\
- & \text { Environment, learning, culture, } \\
\text { etc } & \end{array}$ \\
\hline
\end{tabular}

\section{Actual Cases on Smart City}

\subsection{Cases of Europe}

In the U.K., the positive social atmosphere toward smart city has been expanded since the Glasgow project. In 2007, the U.K. government established a special committee called TSB for the future construction and technology-centered innovation of the U.K. The committee planned the 'Smart City' project and collected proposals from local governments in 2012, and finally, Glasgow was selected as the target city.

In 2013, Glasgow decided to carry out its 'Smart City' development project in cooperation with IT companies such as IBM and Intel. With Glasgow as the first example city of this future city program planned by the technology strategy committee of the U.K., the U.K. government is planning to establish the second and third smart cities in major metropolitan cities such as London, Birmingham, and Sunderland.

In early 2013, IBM was selected to develop Glasgow smart city. IBM is planning to build up Glasgow smart city as a sustainable community where low carbon technology, cost-saving residence, and cost-efficient heating system are applied. For the embodiment of 'customized' smart city, IBM grasps fundamental problems based on urban elements such as safety, traffic, public health, energy, environment, GDP, and population collected through its own Web sites and represents smart city in application of technologies essential for a city [8]. According to its analysis, IBM will realize a heating system in Glasgow far better than in other regions.

In London as well, the smart city project will be implemented in cooperation with Intel. In the early stage, special sensors will be added to major facilities such as building, streetlight, etc., in order to collect data on noise, pollution, and energy consumption, which will be used in building up a smart city. To this end, Intel has concluded MOU of mutual cooperation with Imperial College and University College London, major IT 
colleges in London, and is planning to implement a thorough survey on the city regarding IT, business models, environments, and commercial viability as a preliminary step for joint development.

As an IT company, IBM released Smarter Planet Initiative Program in 2008 in combination of IT devices such as sensor, networking device, software, etc. After installing them on urban structures(railroad, street light, and building), it collected information about the city by means of IT devices and managed systematically in application of self-developed programs. IT infrastructures that IBM pursues features '3is', that is, the combination of instrumentation, interconnectedness, and intelligence, are core elements for smart city.

In Rio de Janeiro, Brazil, 'Smart City Intelligent Management Center' has been operated to develop an IT system to cope with emergency situations including natural disasters such as flood and landslide, which would often occur in that region. To prevent crimes, new CCTV technology was introduced to the system and collected urban information through sensors all over the city. An operation center to collect and manage the data also was successfully established.

Smart city features supply of electric power to the city by means of a smart grid (intelligent power network) of major buildings (building, plant, and housing) and systems that directly affect the city's economy, energy, and traffic. Hence, IT systems and related facilities are essential. Since traffic control is an important factor in the U.K., it is planned to systematically collect and manage information over major spots of traffic congestion in smart city. Accordingly, the demands for CCTV and related control system software are expected to increase. In addition, as demands for facial recognition cameras for crime prevention, tax management system, energy consumption measuring devices for energy efficiency maximization, and weather prediction equipment are likely to increase continually, domestic IT companies in those areas will have much chance to advance into the markets.

'Cross Roads' in Denmark is a smart city project of Copenhagen, Denmark, initiated in 2002. In the 1990s, plans around Copenhagen transferred to Eastern Europe and Asian regions for low-wage earners. As a result, the former plants and harbor areas became slums. With the aim to foster a new dynamic force for manufacturing industry in these areas, Copenhagen implemented the "Cross Roads' project. "Cross Roads" means a city that combines cultures, media, and communication technology. "Living Lab", a key element to 'Cross Roads' is a concept of laboratory which will accommodate people's desires regarding residential environments and present directions for a future city. The goals of "Living Lab" are presented in Figure 3.

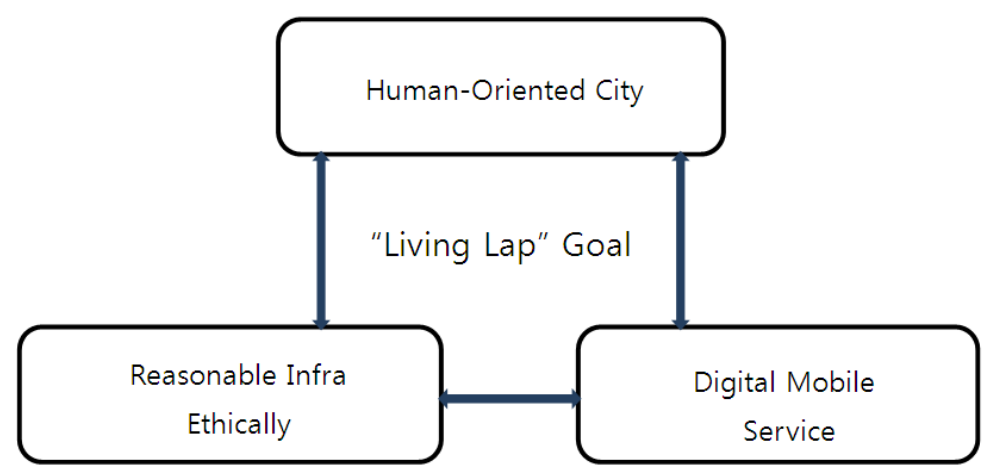

Figure 3. Goals of "Living Lap"

First of all, "Human-oriented City" indicates that the city will focus on humans rather than technology itself and let citizens decide which service will be useful for humans. "Digital Mobile Service" provides a multi-functional program that helps users in whatever 
situation they might be in through various contents. This plays a role as a knowledge bank for digital communication service too. Lastly, "Reasonable Infra Ethically" means that whether the services available in a city are ethically reasonable and useful in specific aspects is examined.

Currently, the district of 'Cross Roads' in Copenhagen is occupied by many colleges including IT University of Copenhagen, private companies including Nokia and HP, public agencies including Denmark broadcasting system and Royal library, etc., 'Cross Roads' is advancing into a global R\&D city through the networking of cultures, media, and communication technologies among the city, individuals, and companies.

The SmartSantander project in Spain aims at 'Smart Urbanization' of Santander in the Northern part of Spain by applying various IT systems. The budget allotted for this project by EU amounts to 8670,000 euro in total, and the four-year plan for the smart city was initiated in September 2010. Since this SmartSantander project focuses on application of cutting-edge information technologies into the city rather than energy saving, more than 20,000 units of sensors, collectors, and cameras were installed in the city so that public agencies, private companies, and civilians can grasp the city situations realtime. More than 20,000 devices distributed over the city are connected to on the integrated system through which information of weather, traffic situation, traffic congestion, and coastal condition is provided realtime, and it is also possible to manage noise, sprinklers, and school security systems by means of the remote control system.

\subsection{Cases of Asia}

The intelligent traffic signal control system of Kuala Lumpur, the capital city of Malaysia, controls the traffic flows over congested areas in the city. The government funded 560,000 dollars for R\&D of the core device of the intelligent traffic signal control system. This system was designed for integrated supervision at DBKL, and it will be combined with existing ITAKA and SCATS system too. 62 traffic management systems will be covered and automatically controlled by this system. The core section of this system is the cutting-edge signal controller, which collects information of traffic flows in advance and controls traffic lights accordingly. To grasp traffic flows, controlling the intervals of signal light cycles at intersections is the key element.

Signal cycle control at intersections in reflection of traffic flows is to minimize the waiting time at intersections. The main concern is to promote smooth flows of vehicles by minimizing the waiting time more than that under the existing intersection traffic light system with fixed patterns of a signaling cycle. Since traffic flows are observed realtime by means of the traffic detecting sensors at each site, traffic light cycles are adjustable depending on the traffic at different times of the day. The best switching timing is determined to reduce waiting time and congestion at each intersection. In addition, the traffic information is shared with adjacent intersections through a $3 \mathrm{G}$ wireless communication network for a streamlined control.

Traffic-sensitive signaling system shares the traffic volume and traffic light cycle at one location with other intersections for the general management. Each center can grasp the traffic light on/off status, signaling cycle, and traffic volume in each intersection realtime, and such information will be utilized to reduce the delay time on the road. This traffic light system displays a green light as a vehicle approaches in order to minimize the delay time of vehicles before congestion occurs as excessive traffic volume passes through the intersection. To realize this type of control system, it is vital to develop software that monitors and reflects the traffic volume. The traffic pattern may be varied at each intersection depending on the times of the day, conditions at adjacent intersections, etc., and a traffic light cycle algorithm needs to reflect such changing traffic conditions. The traffic volume at peak times of each intersection is to be recognized and reflected in the traffic light changing cycle by an artificial intelligence algorithm. In this regard, developing synchronization software to alleviate peak traffic volume is a key factor. 
China is planning to invest 300 billion yuan for the formation of 320 smart cities by 2015. To this end, the Chinese government announced 90 demonstration areas for smart city development in January 2013 and then confirmed 103 areas on August 5. The demonstration areas are subject to various supports from the Chinese government.

Smart city is a future-oriented cutting-edge city that networks major facilities and public functions of a city by integrating cutting-edge ICT elements such as Cloud computing. The Chinese government is carrying out careful urbanization policies in order to minimize adverse effects of rapid economic development such as insufficiency of energy, environmental pollution, etc. and continue the growth by forming a 'Smart' city. At present, the urbanization project in China aims to change the quality of cities drastically by means of security system, infra facilities, smart city construction and management, etc.

The Chinese government is planning to form 320 smart cities in different regions by 2015, beginning from Ningbo in 2010. Ningbo started its integrated construction of smart city in 2011 and is planning to invest about 2.58 billion dollars into cutting-edge city construction, commercial area reconstruction, and smart grid industry development up to 2015. The current government announced its plan to invest 300 billion yuan (about 51 trillion won) into smart city construction in more than 320 cities during the 12.5 zoning period. On December 5, 2012, the Chinese government announced the areas selected for smart city development and plans for management. Smart city construction in China is still in its initial stage, and policies of each local government in this regard may be different from one another. Thus, it is necessary to pioneer the market based on a thorough analysis on specific policies and corresponding strategies. Domestic IT companies with technical competitiveness in such areas as security facility in connection with remote system, energy-saving LED lighting, etc. may seek advancing into China.

Smart grid indicates basic energy infrastructure of future cities where the overall city becomes compact and efficient energy management by demand and supply management is possible. Looking into dispersion development form, power plants will become small and various based on houses, buildings, factories to relieve environment issues with high proportion of new and renewable energy.

Intellectual power network organically links various power plants, transmission facilities, power consumers to one power facility based on information communication network and is expected to include self-therapy functions. Information changing by realtime will be possible between power suppliers and demanders through energy demand and supply management to increase management efficiency of the whole city.

Home generators, storage, HEMS, smart meter, furniture, EV charger are elements of home energy management. Energy by HEMS is managed by securing small generators such as solar photovoltaic. Energy usage will be analyzed by real-time to control usable power time and save energy through device control.

Nowadays, cutting-edge IT technology combined in manufacturing industry is showing new change. Smart factor that is appearing in this flow of change can be characterized as convergence of factory and smart technology such as digitalization, intellectual embedded system, ubiquitous sensor network, AI S/W.

Production facilities have intellectual embedded systems to control multi functions as intellectual individual production facilities will accelerate. Along with this, various control systems loaded in production facilities will realize environment of integrated linked management with not need of control protocols or manufacturing company by an integrated platform. Based on this environment, remotely located smart control center workers will automate production and processing. 


\section{Conclusions}

Smart City means a city where public functions available in common cities are networked by means of cutting-edge information/communication technology. Functions necessary for the realization of ICT-based smart city include concepts of sensor-based ubiquitous environment and intelligence. This study comprehensively considers actual cases of smart city, home and abroad, which presents space for most life activities and presents directions for the future briefly by comparing them with smart cities in our society.

The U.K. government has built up Glasgow smart city and is planning to the second and third smart cities in other metropolitan cities such as London, Birmingham, Sunderland, etc. The SmartSantander project in Spain aims at 'Smart Urbanization' of Santander in the Northern part of Spain by applying various IT systems. 'Cross Roads' in Denmark is a smart city project of Copenhagen, Denmark, initiated in 2002. In the 1990s, plans around Copenhagen transferred to Eastern Europe and Asian regions for low-wage earners."Living Lab", a key element to 'Cross Roads', is a concept of laboratory which will accommodate people's desires regarding residential environments and present directions for a future city.

The Chinese government is planning to form 320 smart cities in different regions by 2015, beginning from Ningbo in 2010. Ningbo started its integrated construction of smart city in 2011 and is planning to invest about 2.58 billion dollars into cutting-edge city construction, commercial area reconstruction, and smart grid industry development up to 2015.The intelligent traffic signal control system of Kuala Lumpur, the capital city of Malaysia, controls the traffic flows over congested areas in the city. The government funded 560,000 dollars for R\&D of the core device of the intelligent traffic signal control system.

\section{References}

[1] NIA, "Convergence between IT based Industries and Strategy direction of National Information",(2010).

[2] J. Hangbae,"Future of Smart Technology", LG CNS, (2010).

[3] NIA,"Future City through Smart City",IT\&Future Strategy, (2010).

[4] IDG Korea,(2012).

[5] S. H. Lee and D. W. Lee, “A Study on Digital Convergence and Smart City”, Journal of Digital Policy \& Management, vol. 11, no. 9, (2013), pp. 167-172.

[6] L. Figueiredo, I. Jesus, J. A. T. Machado, J. R. Ferreria, J. L. Martins de Carvalho, "Towards the development of intelligent transportation Systems", Proc. IEEE Intelligent Transportation Systems,(2001), pp. 1206-1211.

[7] F. Y. Wang, C. Herget, D. Zeng,"Developing and Improving transportation systems, The Structure and operation”,IEEE Trans. Intelligent Transportation Systems, vol. 6, no. 3, (2005), pp. 261-264.

[8] Pike Research,"IBM Raises the Stakes in the Smart City Technology market with its Intelligent Operations Center",(2011).

[9] Navigant Research,"Smart City",(2013).

[10] United Nations, "Department of Economic and social Affairs-World Urbanization Prospects".

[11] R. Giffinger,"Smart Cities: Ranking of European Medium-Sized cities, Centre of Regional Science", Vienna University of technology.

[12] M. K. Nayak, S. Mohanty, R. Soni, "People and Skills: A Potential Risk in ICT Infrastructure Management", International Journal of Software Engineering and Its Applications, vol. 5, no. 3, (2011), pp. 135-142.

[13] Q. Liu, “An Intelligent Managing System of Electric Energy based on ST7538”, International Journal of Smart Home, vol. 9, no. 2, (2015), pp. 253-264. 


\section{Authors}

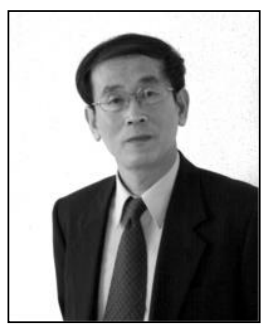

Seong-Hoon Lee, (MSc'95-PhD.'98) He receivedthe M.Sc. degreeof Computer Science and Engineering from Korea University, Seoul, Korea in 1995, and the Ph.D. degree of Computer Science and Engineering from Korea University, KOREA in 1998. Since 1998, he is a Professor in School of Information and Communication, BaekSeokUniversity, Korea. His main research interests include Distributed system, Grid Computing, Web Service, etc.

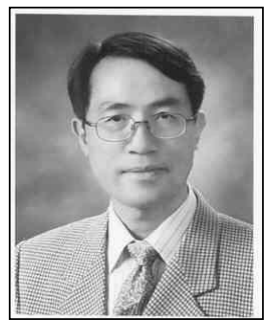

Dong-Woo Lee, he received his BS in electronic engineering, $\mathrm{MS}$ in computer engineering, and $\mathrm{PhD}$ in computer science from Korea University, Korea. He joined the department of computer information science, Woosong University, Korea at 1995 . He is currently a professor. His research interests include distributed processing and systems, database, and reactive systems. (Corresponding author of this paper). 